\title{
Olhos luminosos e peles de metal
}

\author{
Danilo Paiva Ramos \\ Carolina de Camargo Abreu \\ - Universidade de São Paulo / São Paulo, SP, Brasil \\ $\checkmark$ dpaivaramos@gmail.com \\ caroldca@usp.br
}

El abrazo de la serpiente

Filme de Ciro Guerra

(Colômbia, 2015, 123 min.)

De certo, El abrazo de la serpente não é um filme etnográfico. Apesar disso, qualquer etnógrafo que assista reconhecerá, na ficção, os detalhes realistas

e minuciosos das descrições atentas daqueles que inspiram e fundamentam boa parte do roteiro: Theodor Koch-Crünberg e Richard Evans Schultes. E, talvez, cineastas e literatos reconheçam na trama os rastros de um bom romance de cavalaria, a nova busca de um santo graal-alucinógeno, ambientada não nas florestas temperadas e estepes europeias, mas na selva tropical amazônica. Vencedor de prêmio em Cannes e indicado ao Oscar, o longa de 2015 dirigido por Ciro Guerra e escrito por Jacques T. Vidal pretende-se também um documento crítico forjado a partir de um "ponto de vista indígena". Visa a denunciar o extermínio de povos pela violência da exploração da borracha, escancarar o terror e a insanidade das missões católicas e questionar a paradoxal razão científica, chave para a compreensão intercultural, mas instrumentalizadora da guerra, do capitalismo e da intolerância. Entretanto, ao final do filme, os olhos luminosos de Karamakate, xamã-herói da trama, expressariam mesmo uma "perspectiva ameríndia", ou espelhariam apenas os olhos brilhantes do diretor colombiano na pele das estatuetas de metal europeias e norte americanas?

Definindo o filme como uma viagem ao coração do Amazonas inspirada pelos diários dos exploradores que percorreram a região no início do século xx, Ciro Cuerra sintetiza o enredo como sendo a história de Théo, um etnógrafo à beira da morte que precisa de um xamã-guerreiro para curá-lo'. Este pajé é Karamakate, sobrevivente de um povo dizimado pela exploração da borracha. Para curar Théo, o xamã tem que encontrar os demais sobreviventes de seu povo e 1 Entrevista de Ciro Cuerra à Esquire Colombiana (13 de maio de2015). uma planta medicinal fictícia, a yakruna, árvore de flores brancas que vai se tor- 
nando a metáfora onírica do filme. Passado, presente e futuro vão justapondo as trajetórias do etnógrafo à do etnobotânico Evan que, quarenta anos depois², encontra o velho Karamakate e com ele viaja em busca da yakruna. Enquanto os cientistas têm nos diários, câmeras fotográficas e mapas suas formas de registro e memória, o xamã vai mostrando como através de sonhos, do uso do caarpi, das visões e da viagem, importantes revelações permitem outros modos de conhecer, perceber e entender a existência. A todo o momento, os maus entendidos, os risos, as desavenças e cuidados curativos vão evidenciando as diferenças e semelhanças, os antagonismos e empatias de pessoas, indígenas e não indígenas, situadas entre mundos em contínuo desequilíbrio e tensão.

A mudança constante da perspectiva da câmera entre a primeira e a terceira pessoa, a revelação de detalhes dos elementos e seres da floresta são recursos que criam a experiência fílmica como um jogo de alteridades. Ora caminhamos pisando pelas folhas da selva, ora observamos, já com alguma distância, os corpos e diálogos - tantas vezes incompreensíveis - dos personagens, como que por sobre seus ombros. Os planos fechados em detalhes dos rostos, da floresta, nos objetos de interesse, os ensaios imagéticos com diferentes texturas parecem tentar nos convencer que pegamos emprestados o olhar e o corpo daqueles personagens. Através deles somos convidados a uma experiência cinematográfica do realismo fantástico sul-americano ${ }^{3}$.

A escolha estética do Preto e Branco ( $\mathrm{P} \& \mathrm{~B})$ para a fita torna o filme impressionante. O P\&B não apenas ressalta a exuberância das formas da floresta e a diferença dos contornos humanos, mas principalmente, e deliberadamente, encena o documento, neste caso, o documento antropológico. Ainda a trama do filme se faça como imbricação de diferentes planos e gêneros discursivos - mitos e narrativas de sonhos, relatos de cadernos de campo, profecias xamânicas-, o filme ancora-se, precisamente, na força da retórica da escrita etnográfica ${ }^{4}$.

O xamã Karamakate pode ser situado como o polo "tradicional-moralizador-puro" da trama, propiciador de um fluxo de identificação contínua ao longo do filme. Menos um diplomata e mais um cavaleiro-juiz, ele é o guardião de práticas e saberes ancestrais. Jovem, o xamã é capaz de curar, guiar e orientar o etnógrafo. É capaz de repreender os sobreviventes de seu povo pela rendição aos "brancos" e pelo mau uso dos conhecimentos xamânicos. Velho, Karamakate é guiado pelo etnobotânico num percurso que vai curando seu esquecimento, seu estado de Chullachaqui à medida que revela e transmite seus conhecimentos ao cientista. Enquanto Théo, o primeiro viajante, parece ser um estudioso comprometido com a descrição e entendimento do universo indígena, mas com um terrível e egoísta medo da morte; Evan devota sua vida às plantas e volta-se ora à yakruna, por suas propriedades medicinais, ora à seringueira, pelas possibilidades para a indústria da borracha num período de guerra. Com "roupas de bran-
2 No filme o personagem etnógrafo Théo viaja para a Amazônia em 1903 e etnobotânico Evan em 1941.

3 Aproveitando expressões de Gilberto Perez e André Bazin, David Mac Dougall (2006) pontua que a presença não é uma ilusão no cinema, mas uma alucinação que é verdadeira em seus efeitos. Mac Dougall, antropólogo cineasta, considera o filme recurso poderoso de perturbação das fronteiras entre a percepção sensorial e a memória (ou sonho).

4 Vale lembrar como O abraço da serpente, dois anos entre os indigenas [1909] - que conta a viagem de Koch-Grünberg entre $1903 \mathrm{e}$ 1905 -, foi um grande sucesso na Alemanha, tendo suas primeiras edições rapidamente esgotadas (Kraus, 2004). 
co", marcado pela violência dos patrões da borracha, mas ainda conhecedor da cosmologia e língua de seu povo, Manduca é o guia e companheiro indígena do explorador alemão, em contraste permanente com o protagonista xamã. Esse complexo jogo de espelhos entre os personagens cria oposições tensas entre o "índio tradicional" e o "índio caboclo", entre o "cientista humanista" e o "cientista especialista".

Os "atores indígenas", também chamados de não atores em muitas mídias, contracenam com os ditos "atores internacionais", ou "atores profissionais" Jan Bijvoet (Théo) e Brionne Davis (Evan). Nilbio Torres, que assume o personagem Karamakate, conta que ao aceitar o convite para trabalhar no filme pensava que ajudaria na logística ou no carregamento de equipamentos. Surpreendeu-se ao ser convidado a interpretar o papel principal. O senhor Antonio Bolivar (Karamakate mais velho) diz que aceitara a atuação como uma forma de luta pelo seu povo Ocaina. Queria mostrar aos jovens a importância de seus costumes e história. Nas pausas da filmagem, contam que muitas vezes se sentiam tristes ao encenar momentos tão difíceis da história dos povos da região. Já o ator belga Jan Bijvoet afirmou à mídia EfE que "Cuando escuchas esas terribles historias (de opresión y muerte contra los indígenas), te sientes culpable, obviamente. Los blancos hemos hecho tropelías en todos los sitios (...). Y aún las seguimos haciendo" (EFE, 2016). Por um lado, o encantamento com os contrastes P\&B de uma paisagem amazônica exuberante ergue o cenário para a valorização das práticas, substâncias e conhecimentos xamânicos "tradicionais" como os sonhos do caarpi, as conversas da coca (conhecida como mambe) e da viagem da yakruna. Por outro, a denúncia a partir de um ponto de vista indígena" aponta a violência e terror das missões e da exploração da borracha que causam a decadência de uma cultura indígena genérica existente apenas nas memórias do velho xamã refugiado.

O abraço da serpente faz uso extenso de estratégias discursivas da autoridade antropológica para imprimir efeitos de verdade à própria ficção. Essa operação mostra-se escancarada pelo uso de fotografias dos diários de Koch-Crünberg montadas junto aos créditos finais da película, e então anunciadas como registros raros, etnográficos. Nas palavras do diretor:

Me baseei nos diários dos exploradores inicialmente, mas quando fui para a Amazônia, isso era completamente diferente do que eles documentaram. Não temos uma memória coletiva desse tempo como sociedade. É uma época perdida. A ideia era voltar a isso, trazer isso de volta mesmo que isso não existisse mais. Isso existiria novamente no filme (Ciro Cuerra). ${ }^{6}$

O longa busca revelar-se como uma simulação fílmica da experiência
6 VICE, Camilo S. "El Abrazo de la Serpiente' é um filme violento e psicodélico sobre a colonização da Amazônia". Folha de São Paulo-2 de setembro de 2016. Disponível em: http://www1.folha.uol.com. br/ilustrada/2016/01/1728989-el-abrazo-de-la-serpiente-e-um-filme-violento-e-psicodelico-sobre-a-colonizacao-da-amazonia.shtml. Acesso em: 31 de agosto de 2016. 
amazônica, quando, na verdade, sustenta-se como um simulacro. E, embora o simulacro seja a representação de elementos que nunca existiram ou que não possuem mais o seu equivalente na realidade, o simulacro é verdadeiro, ressalta Eclesiastes: "[o] simulacro nunca é aquilo que esconde a verdade -é a verdade que esconde que não existe" . Nesse sentido, o encanto e a nostalgia com os "povos dos diários" parecem cegar o cineasta quanto aos "povos diante de si". Em seu "pessimismo sentimental" (Sahlins, 1997), Guerra procura recriar o passado sem valer-se do modo como os habitantes da região contam a história do Uaupés ${ }^{8}$. Convida atores indígenas, vale-se de minuciosas descrições etnográficas sem, no entanto, dar voz àqueles que poderiam ser seus interlocutores e cocriadores.

Um dos pontos destacados pelo diretor como uma virtude do filme é a variedade de línguas utilizadas. Os diálogos são expressos em ocaina, ticuna, cubeo, espanhol, português, alemão, latim e catalão. Em entrevista para a mídia Cinéfilos Colombia9 , o ator Nilbio Torres, da etnia Cubeo (o jovem Karamakate), conta que a maior dificuldade que ele, Antonio Bolivar (Karamakate velho), da etnia Ocaina, e Miguel Ramos (Manduca), da etnia Ticuna, tiveram durante as filmagens foi a comunicação entre si. Durante as gravações, precisavam falar suas línguas maternas, mas sem compreenderem um a língua do outro (ocaina, ticuna e cubeo). Se aos ouvidos do espectador não indígena ecoa uma mesma e exótica língua, inteligível rapidamente pelas legendas, os diálogos entre os atores seguiram como um simulacro de comunicação representada, fruto de uma situação de incompreensão verbal.

O simulacro pode ser observado também quanto a outros aspectos culturais representados. As imagens cosmológicas da serpente astral, da árvore florida (yakruna), do mestre caarpi e da onça onírica delineiam os contornos de uma espécie de xamanismo genérico, já que tais elementos são extraídos de diferentes povos e regiões e, muitos deles, não estão presentes no Uaupés. Tais elementos são articulados pelo realismo fantástico do cineasta que vaga entre a "retórica salvacionista"10 e o neoxamânismo a desnudar os limites da razão. O filme constitui, assim, um forte "ponto de vista artístico-acadêmico" a partir de simulacros linguísticos, cosmológicos, étnicos e historiográficos que criam um efeito especial de "ponto de vista indígena" estetizado num compromisso saturado com o belo, o puro e o tradicional.

Sem terem sido convidados para a exibição regional do filme, os benzedores puinave manifestaram sua apreensão com relação à saúde e vida dos atores e equipe de filmagem ${ }^{11}$. As cenas finais foram rodadas em paisagens que correspondem a seus lugares sagrados. Montanhas e corredeiras habitadas por poderosos "Donos"12, onde são encontrados os rastros de seus ancestrais, são paisagens míticas onde os xamãs puinave colhem plantas curativas e realizam práticas rituais fundamentais para a cura e proteção de seu povo. Sem terem
7 Citado por Jean Baudrillard, em Simulacros e Simulação (1981). O discurso de simulação não pode ser desmascarado, pontua Baudrillard, porque não é falso. Limítrofe é a distinção entre o verdadeiro e o falso, do que é produzido e do que é autêntico. Imita tão bem que torna-se um. "[F] ingir, ou dissimular, deixa intacto o princípio da realidade: a diferença continua a ser clara, está apenas disfarçada, enquanto que a simulação põe em causa a diferença do verdadeiro e do falso, do real e do imaginário". (Baudrillard, 1981: 10)

8 Região amazônica que abarca o Estado do Uaupés, no lado colombiano, e parte do Alto Rio Negro, no lado brasileiro da fronteira.

9 Entrevista à mídia Cinéfilos de Colombia de 27 de maio de 2015

11 Laszorilas. Mal estar por El Abrazo de la Serpente. Disponível em: http://www.las2orillas.co/ malestar-indigena-por-el-abrazo-de-la-serpiente/. Acesso em: 30 de agosto de 2016

12 Seres que exercem domínio sobre lugares e certos grupos de animais. 
sido consultados sobre as filmagens em seu território, as lideranças puinave dizem temer o turismo. Após o filme, dezenas de não indígenas começaram a dirigir-se para a região desejando visitar o cenário do longa. Lideranças mais revoltadas denunciam o desrespeito ao direito de consulta prévia e informada previsto pela Constituição Colombiana e exigem reparações. Comprometido com a denúncia do extermínio de povos indígenas genéricos, O abraço da serpente parece não ver nas populações locais reais interlocutores fundamentais seja para o diálogo criativo, seja para o respeito moral e ético.

De fato, $\mathrm{O}$ abraço da serpente explora com grande competência as possibilidades sensoriais da narrativa audiovisual. É um filme visceral, que acessa alguns dos ritmos dos fluxos fluviais, das febres e calafrios amazônicos. Se, por um lado, somos transportados para o contexto da selva através do uso preciso de técnicas cinematográficas, por outro, a ausência de referências históricas e a justaposição entre o presente fílmico e os diferentes tempos históricos não datados dos personagens constrói imagens "eternas do passado" (cf. Benjamin, 1994) e (re)produz uma certa experiência mítica. Tal experiência, entretanto, desprovida de compromisso ético, de real interlocução com as populações locais, é oca, vazia como a noção êmica fictícia do Chullachaqui.

No dia 20 de abril de 1903, o então auxiliar científico do Museu Etnológico de Berlim Theodor Koch-Crünberg deixava a Alemanha rumo ao Brasil para a realização da expedição etnográfica que o levou a conviver por anos com interlocutores indígenas da região do Alto Rio Negro-Am (Kraus, 2004). Sobre a obra de Koch-Grünberg, Schaden dirá que "como poucos, soube ver sempre no habitante das selvas o seu semelhante, o ser humano merecedor de profunda simpatia e de grande amizade" (Schaden, 1953: 135). Em O abraço da serpente, apesar da riqueza de detalhes embasada pelos diários etnográficos, não temos acesso ao ponto de vista humanista de Koch-Crünberg ou de Richard Evans Schultes que conviveram anos com os povos da região. Procurando e orgulhando-se de reconstituir, cinematograficamente, um "ponto de vista indígena" sobre a Amazônia, o filme fabrica um complexo simulacro que nada mais expressa que o próprio "ponto de vista do cineasta" com o qual nos identificamos, tal como num bom livro de Gabriel García Márquez.

Danilo Paiva Ramos é mestre (2006) e doutor (2014) em Antropologia Social pela Universidade de São Paulo. Realizou pós-doutorado em Antropologia Linguística pela Universidade do Texas (2015-2016, BEPE-Fapesp), e agora é pós-doutorando também em Antropologia Social pela usp. Coordena o Grupo de Estudos de Antropologia e Linguística (CEAL-USP). 
Carolina de Camargo Abreu é mestre (2006) e doutora (2012) em Antropologia Social pela Universidade de São Paulo. Membro do Núcleo de Antropologia, Performance e Drama - Napedra e pesquisadora associada ao Grupo de Antropologia Visual-Gravi e ao Núcleo de Antropologia Urbana - NAU.

\section{REFERÊNCIAS BIBLIOGRÁFICAS}

\section{AGÊNCIA EFE}

2016 "El abrazo de la serpiente" trata sobre no prejuzgar, dice su protagonist. Disponível em: http://www.efe.com/efe/america/cultura/el-abrazo-de-la-serpiente-trata-sobre-no-prejuzgar-dice-su-protagonista/20000009-2787817. Acesso em: 30 de agosto de 2016.

BAUDRILLARD, Jean

1981 Simulacros e simulação. Lisboa, Antropos.

BEN]AMIN, Walter

1994 "Sobre o conceito de história". In ., Magia e técnica, arte e política: ensaios sobre literatura e história da cultura - vol 2. Tradução: Sergio Paulo Rouanet. São Paulo, Brasiliense.

\section{CINÉFILOS DE COLÔMBIA}

2016 El Abrazo de la Serpente-Entrevista-Nilbio Torres. Disponível em: https://www. youtube.com/watch?v=DBWrPP6IF3A. Acesso em: 30 de Agosto de 2016.

\section{EL ESPEJO}

2016 El Abrazo de La Serpiente (sin cortes) entrevista con Tiapuyama (Antonio Bolivar). Disponível em: https://www.youtube.com/watch?v=yBAwxIC4D-s. Acesso em: 30 de Agosto de 2016.

\section{ESQUIRE COLOMBIANA}

2016 Ciro Guerra / El abrazo de la serpiente. Disponível em: https://www.youtube. com/watch?v=7YUBoeq87CM. Acesso em: 31 de agosto de 2016.

FABIAN, Johannes

1983 O tempo e o outro. Petrópolis, Editora Vozes. 


\section{LAS2ORILLAS}

2016 Mal estar indígena por El Abrazo de la Serpente. Disponível em: http://www. laszorillas.co/malestar-indigena-por-el-abrazo-de-la-serpiente/. Acesso em: 30 de agosto de 2016

KRAUS, $M$.

2004 "Y cuándo finalmente pueda proseguir, eso solo ló saben lós dioses". Boletín de Antropología, Medellín, v. 18, n. 35: 192-209.

MAC DOUGALL, David

2006 The Corporeal Image. Film, Ethnography, and the Senses. Princeton e Oxford, Princeton University Press.

SAHLINS, Marshall

1997 “O 'pessimismo sentimental' e a experiência etnográfica: por que a cultura não é um 'objeto' em via de extinção”. Mana, Rio de Janeiro, v. 03, n. 01: 41-73.

SCHADEN, E.

1953 “A obra científica de Koch-Crünberg”. Revista de Antropologia, São Paulo, v. 1, n. 2:133-136.

VICE, Camilo S.

2016 "'El Abrazo de la Serpiente' é um filme violento e psicodélico sobre a colonização da Amazônia". Folha de São Paulo-2 de setembro de 2016. Disponível em: http://www1.folha.uol.com.br/ilustrada/2016/01/1728989-el-abrazo-de-la-serpiente-e-um-filme-violento-e-psicodelico-sobre-a-colonizacao-da-amazonia.shtml. Acesso em: 31 de agosto de 2016. 